\section{$X$-RAY Findings}

About four months ago the girl was brought to me for an $x$-ray examination. The lateral view of the spine shows the relation of the parts, and a skiagram of the feet demonstrates the associated trophoneurosis in the deformity of the terminal phalanx of the left great toe, with premature union of its epiphysis, and in the outline of the soft tissues. (See figures on Plate.)

The upper portion of the lumbar spine consists of poorly developed vertebrae, and is directed downwards and backwards. The fourth vertebra is better developed, and is directed upwards and backwards, so that its articular surface lies at right angles, instead of being nearly parallel, to the upper portion. The laminae of the third and fourth vertebrae appear to have become united, and thus give some security, but in all probability the chief source of stability is ligamentous union, together with an intervertebral disk on the superior surface of the fourth vertebra. By that means the weight of the body is being transmitted to the pelvis, but on account of the obliquity of the opposing surfaces the weight is borne by the spinal column at considerable mechanical disadvantage, so that part of the weight is tending to increase the deformity.

The antero-posterior view of the spinal column shows a marked scoliosis of both the dorsal and lumbar regions. As one would expect, the lumbar spine shows a greater breadth than normal, but it shows nothing to indicate that the lateral view would reveal such definite evidence of altered structure.

\section{General Clinical Features}

Both lower limbs are remarkably well developed, but the left foot is slightly smaller than the right. There is neither paresis nor wasting of the muscles of the left leg as far as the ankle. Flexion and extension of the left ankle can be performed in a normal fashion, but dorsiflexion of the left toes can be carried out only to a very slight degree; plantar flexion and abduction of these toes cannot be effected at all. The movements of the right foot are normal, and sensation also is normal. There is anaesthesia of the left leg and foot from a line about two fingerbreadths below the knee. This area of anaesthesia corresponds to the segmental cutaneous distribution of the fourth and fifth lumbar and the first sacral nerves. Over this area the patient is unable to feel the prick of a needle, or to distinguish between a test tube of cold water and one of hot water. From time to time the skin on the plantar surface of the left great toe becomes black, and gives rise to a painless ulcer; but at present there is no ulcer, and the only clinical evidence of trophoneurosis is the diminution of the pad of soft tissue on the plantar aspect of the terminal phalanx, and the greatly thickened, hardened, and flattened epidermis. The tip of the left second toe is somewhat reddened, but the skin has never broken down.

In general appearance the girl looks healthy and is well nourished, but as the result of the scoliosis and the lumbar deformity she is only $4 \mathrm{ft} .1 \frac{1}{2} \mathrm{in}$. in height. She is above the average in intelligence, and is a good scholar. She is active on her legs, walks well, and can run about in the usual children's games. She has not had any of the infectious diseases of childhood, nor has she had nocturnal enuresis or any rectal trouble.

\section{Comments}

Because of the condition of her back she was not encouraged to take to her feet early, and did not begin to walk until she was $2 \frac{1}{2}$ years old. At 5 she was fitted with a plaster jacket, which she wore for three years, and after that had a special form of corset, not very stiff, and laced with elastic. This she continued to wear until, as the result of the radiographic findings, she was fitted with a new jacket, of cage-like pattern, constructed with light bars of aluminium, incorporating a crutch under both armpits and a band of aluminium round the upper part of the pelvis, to avoid as far as possible any undue strain on the lumbar dislocation. Dr. John Reid of Forth, Lanarkshire, who had been present at the birth of this girl, states that he remembers her, and " certainly thought that the swelling in the lumbar region when she was born was a spina bifida. It was quite soft."

It appears, therefore, that the nature of the swelling is beyond reasonable doubt, and that it should be regarded as an example of spontaneous cure of a spina bifida associated with congenital dislocation of the lumbar spine. Not all cases of spina bifida are associated with such great alteration in the bodies of the vertebrae. In many, if not in most, the maldevelopment is confined to the neural arch, which makes it all the more remarkable that this case, showing such a gross disturbance of the vertebral bodies, should have undergone a spontaneous cure. That the child is healthy and intelligent, and appears to have a very good prospect of completing the alloted span, is also noteworthy.

For the opportunity of examining and recording this interesting and rare case $\mathrm{I}$ am indebted to Dr. J. N. Jamieson of Kelvinside, Glasgow, and I am grateful to Dr. John Reid for his reply to my query.

\section{REMOVAL OF AN ASCARIS FROM THE COMMON BILE DUCT \\ BY -}

J. B. G. MUIR, M.B., B.S., F.R.C.S.

PRINCIPAL MEDICAL OFFICER, THE KaIlaN MINING aDMINistration, TIENTSIN, NORTH CHINA

(With Special Plate)

Invasion of the biliary tract by parasitic worms is by no means a rare occurrence. A complete Taenia saginata, ten feet long, has been found in the gall-bladder of an old man operated upon for acute cholecystitis (Benedict). It is more usual, however, for the invading worm to be an ascaris, and Aviles has collected ninety reported cases where ascarides have invaded the common bile duct and, in some instances, reached the gall-bladder, a situation where they have been found forming the nuclei of gallstones. Such invasion is usually complicated by impaction of the worms with obstruction of the common duct. Superadded acute infection results, leading eventually to the death of the host, the cause being discovered post mortem. Thus, at a necropsy on a young girl, six abscesses were found on the surface of the liver, each containing a large coiled-up ascaris (Sivasambandan), and, at another on an infant of 11 months, 300 ascarides were counted in the duodenum alone, others being found in the bile ducts and in cavities in the liver (Sinicco). It is rather unusual, however, to detect, at actual operation, an ascaris in the process of invading the gall-bladder, and for this reason I consider the following case worthy of publication.

\section{Case Report}

A Chinese coolie, aged 35, was seized with violent pain in the upper abdomen at $10.30 \mathrm{a} . \mathrm{m}$. on January $3 \mathrm{rd}, 1932$. He collapsed, and was found lying doubled up on his bed with pain. $\mathrm{He}$ was brought to the Tongshan Hospital at 3 p.m. On admission he was in great agony. He had vomited several times, and his pain was localized to the epigastric region. Pulse 100 , temperature $97^{\circ} \mathrm{F}$. There was marked rigidity of the upper abdomen, and tympanites was present, but liver dullness was unimpaired. Slight icterus of the conjunctivae was 
observed. A white blood count showed a leucocytosis of 21,000 , with 85 per cent. polymorphs. He resembled a case of severe biliary colic with associated acute cholecystitis or a localized duodenal perforation, and as his pulse rate was increasing I decided that exploration was indicated.

\section{Operation}

This was performed at 6.30 p.m. under open ether anaesthesia. The abdomen was opened by a right paramedian incision, and slight intestinal distension was observed, but no signs of peritonitis. The gall-bladder was tensely distended, and the adjacent peritoneum of the gastro-hepatic omentum appeared congested and oedematous. On palpating the neck of the gall-bladder I felt something exactly resembling a piece of whipcord, which could be traced in continuity into the cystic duct, and even more plainly felt in the supraduodenal portion of the common duct. On incising the cystic duct longitudinally, this was found to be an ascaris completely filling the lumen. I seized it with forceps and tried to extract it, but it appeared to be impacted, the forceps cutting through the body. The common bile duct was then incised, and the distal portion of the ascaris, measuring $5 \frac{1}{2}$ inches long, was easily removed with common duct forceps. On removal it still exhibited movements. There now remained the proximal portion of the worm, impacted in the cystic duct and gall-bladder, and these were accordingly removed in the usual way, this portion of the worm measuring $2 \frac{1}{2}$ inches long.

\section{Progress}

As infection of the common duct appeared probable, a fine rubber drainage tube was inserted into it through the exploratory incision in the duct, and retained in position by a fine catgut stitch, being connected through the abdominal wound to a bile-collecting bottle. A large drain was then inserted down to the subhepatic region, through a stab wound on the right of the laparotomy incision, and the abdomen closed. Free bile drainage occurred from the tube in the common duct until the eighth day, when it became loose and was removed. The stools, which had been somewhat clay-coloured, now resumed their normal colour. A little bile and serum continued to drain from the larger tube until the tenth day, when it was removed, the tract closing rapidly. The patient made an uninterrupted recovery, and left hospital twenty-six days after operation. Subsequent anthelmintic treatment with santonin resulted in his passing nine ascarides. The accompanving photograph shows the actual operation findings. The gall-bladder, which has shrunk considerably, is cut open and pinned out to show the proximal portion of the worm protruding into it from the cystic duct, which is ligatured, the ligature including the worm. The larger portion, removed from the common duct, is seen pinned out alongside it.

\section{Commentary}

The most striking clinical feature of this case was the extreme agony exhibited by the patient. I have seldom seen a patient in such pain, except perhaps in a few cases of acute pancreatitis.

Surgical complications of ascariasis are generally caused by the migratory tendencies of the parasites. Although their normal habitat is the small intestine, they may enter the stomach and be vomited; this occasionally happens during post-anaesthetic vomiting. Ascarides have been found in the nasopharynx, appearing through the nose, and may in exceptional cases enter the Eustachian tube and set up acute middle-ear symptoms. They have been known to find their way, via the larynx and trachea, to the bronchi, and set up pneumonia, their ova being found in the sputum. In the abdomen ascarides may complicate, or actually cause, many surgical conditions. Such complications, however, are generally met with in tropical rather than temperate climates, and in countries where, owing to lack of hygienic methods and cleanliness in the preparation of foodstuffs, the individual infection rate of the population is very high. The use of human excreta to fertilize vegetables is a prolific cause of infec- tion, as also is a contaminated water supply. In China, for example, where such conditions are widespread, ascariasis is especially prevalent; the infection rate of the total population is estimated to be as high as 60 to 70 per cent. (Jeffrey and Maxwell). Ascarides may occur in such numbers as actually to cause acute intestinal obstruction. This usually arises through the impaction of a mass of worms in the terminal ileum, and illustrative cases of this have been published by Hamid, Landsborough, and Ryrie. Such mass infection may seem almost. incredible, but the celebrated case reported by Allbutt, where a boy of 12 passed over 5,000 worms in three years and more than 600 in a single day, illustrates in what quantities they may abound in one individual's intestine. It is not uncommon for ascarides to enter the vermiform appendix, and cause trouble by obstructing the lumen. I have twice removed the appendix for acute symptoms, and divided the body of an impacted worm in so doing. Villiger describes a case where, at operation for suspected acute appendicitis in a child of 10, the symptoms were found to arise from a Meckel's diverticulum distended by ascarides.

Unsuspected ascarides may cause troublesome postoperative complications. In April, 1929, I performed a posterior no-loop gastro-enterostomy on a man, aged 40, for a large pyloric ulcer. $\mathrm{He}$ made excellent progress until the tenth day following operation, when persistent vomiting commenced, and it appeared as if some kink or obstruction to the efferent loop had occurred. After gastric lavage, however, he vomited seven ascarides, with complete relief of the symptoms. They had presumably been blocking the efferent loop, a complication which could have been avoided by preliminary anthelmintic treatment. It does not seem likely that an ascaris can penetrate a normal healthy intestinal wall, and its presence in the peritoneal cavity can only be explained by undue thinning, perforation, or ulceration of the intestine. Thus, in surgical practice in the industrial area of North China, where one has to deal with numerous cases of abdominal trauma, it is quite common to remove ascarides from the peritoneal cavity when operating on cases of ruptured or perforated intestine. Their presence, however, does not appear to increase the mortality of such cases unduly, this depending largely, as elsewhere, on the time factor extending between the injury and the operation.

During recent Chinese civil wars, in several cases of faecal fistula following gunshot wounds of the abdomen, treated locally, ascarides were occasionally found under the wound dressing, whence they had made their way from the intestine via the fistulous track. Needless to say, suitable anthelmintic treatment was necessary prior to surgical closure of the fistula.

Consideration of these few surgical conditions and complications caused by ascaris emphasizes how necessary it is for surgeons, operating in a country where this parasitic infection is individually heavy, to subject all casual abdominal operation cases to preliminary anthelmintic treatment prior to operation if there is the slightest evidence of ascaris infection-a fact easily ascertained on routine stool examination for the ova.

Bibliography

Benedict, E. B.: Journ. Amer. Med. Assoc., December, 1926, No. 23, 1917

Aviles, J.: Surg., Gynec. and Obstet., November, 1918, 459.

Sivasambandan, R.: Malayan Med. Journ., June, 1928, No. 2, 101. Sinicco, S.: Arch. Ital. Sci. Med. Col., December, 1927, No. 12, 701.

Jeffrey and Maxwell: Diseases of China, p. 165.

Iandsborough: Quoted from ibid.

Hamid, M.: Egypt. Med. Rev., April, 1927, 266.

Ryrie, G. A.: Malayan Med. Journ., December, 1928, No. 4, 164.

Allbutt: System of Medicine, vol. ii, Part 2, p. 887.

Villiger, E.: Schweiz. med. Woch., September, 1929, No. 36, 909. 


\section{KYLE : SPINA BIFIDA WITH DISLOCATION OF SPINE}

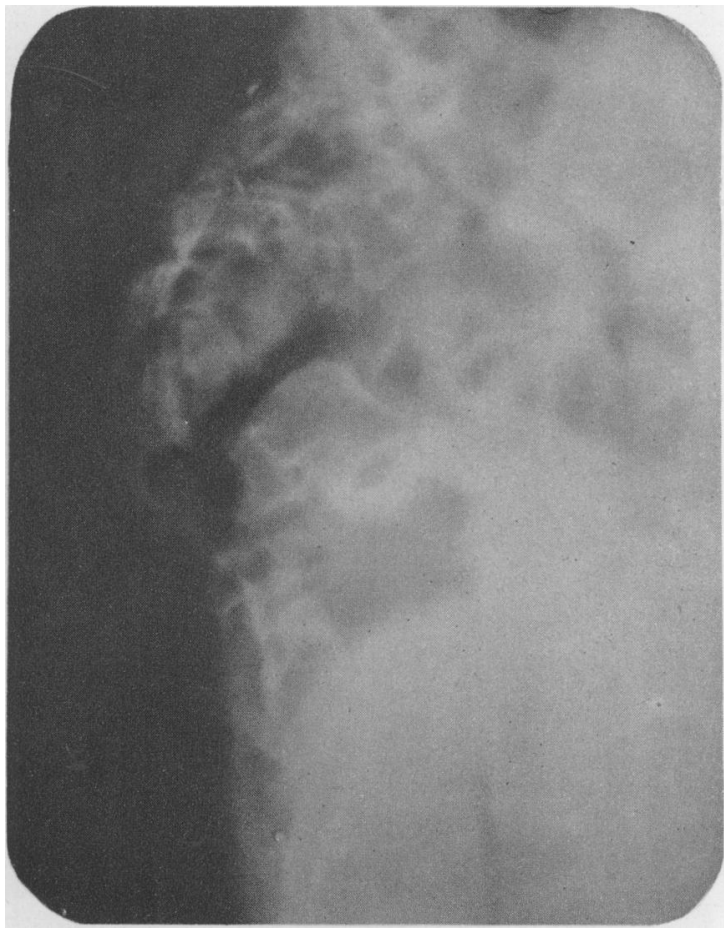

FiG. 1.-Lateral view of lumbar spine (reduced).

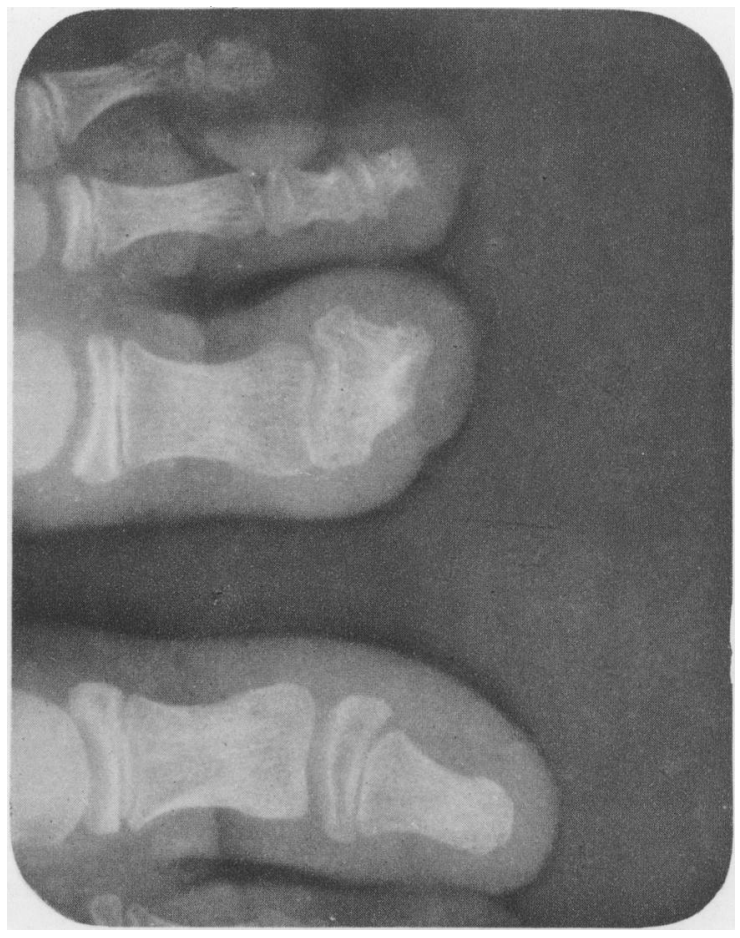

Fia. 8.-Associated trophoneurosis of terminal phalanx of left great toe (antero-posterior view-actual size).
J. B. G. MUIR : REMOVAL OF ASCARIS FROM COMMON BILE DUCT

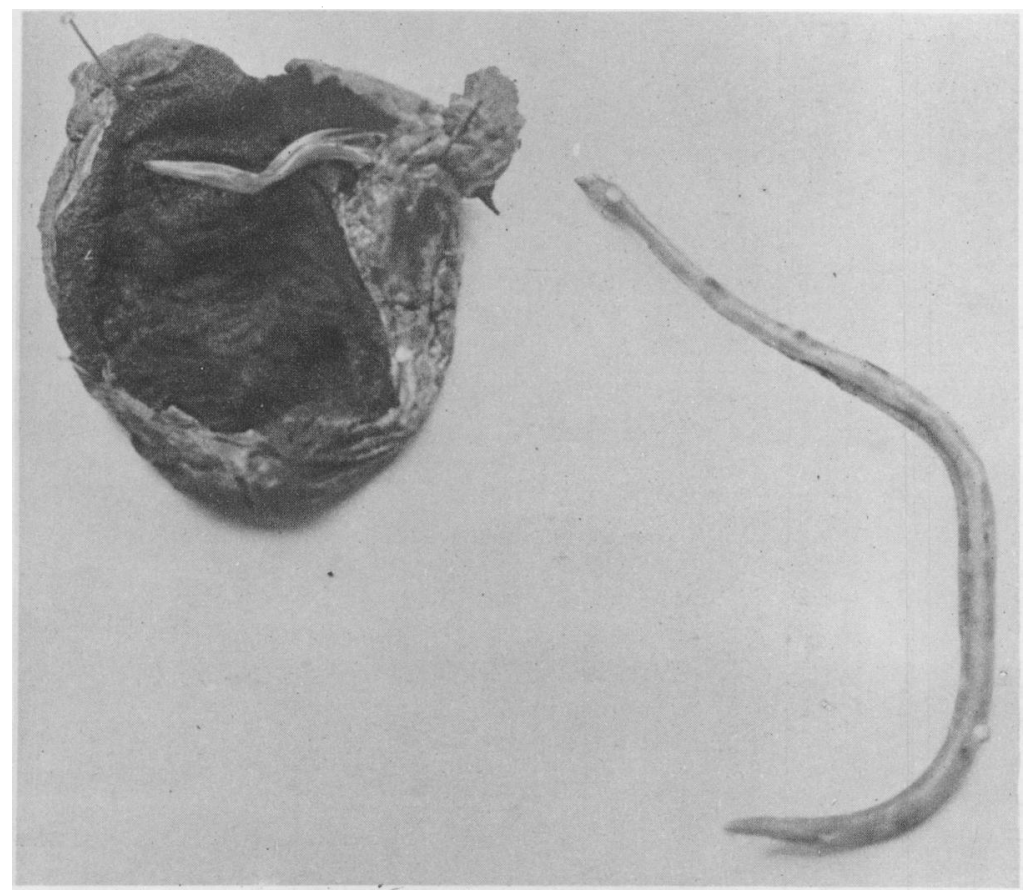

Fia. 1.-Gall-bladder cut open to show proximal portion of worm protruding into lumen. Jistal portion, from common duct, alongside.
G.S. R. LITTLE : UNUSUAL FOREIGN BODY IN FINGER



Fig. 1. - Radiograph showing drop-
lets of nercury in area of swelling.

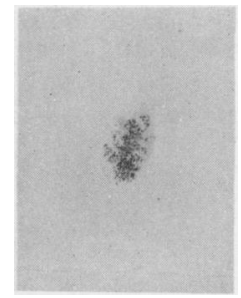

Fra. 2. - Radiograph of flbrous
nodule shrunk down after removal. 